\title{
Comparison of death anxiety among cancer, hemodialysis, and asthma patients and healthy individuals: a cross-sectional study
}

\author{
Seyed-Mehdi Hashemi², Salehoddin Bouya², Mohammadreza Hormozi ${ }^{3}$, Nezarali Moulaei, \\ Alireza Bakhshipour ${ }^{4}$ \\ ${ }^{1}$ Clinical Immunology Research Center, Department of Internal Medicine, Hematology and Medical Oncology Ward, \\ Ali-Ebne-Abitalelb Hospital, Zahedan University of Medical Science, Zahedan, Iran \\ Internal Medicine and Nephrology, Clinical Immunology Research Center, Ali-Ebne Abitaleb Hospital, Zahedan University \\ of Medical Sciences, Zahedan, Iran \\ ${ }^{3}$ Department of Psychiatry, Zahedan University of Medical Science, Zahedan, Iran \\ ${ }^{4}$ Infection Disease and Tropical Medicine Research Center, Resistant Tuberculosis Institute, Zahedan University of Medical \\ Sciences, Zahedan, Iran
}

Neuropsychiatria i Neuropsychologia 2021; 16, 1-2: 82-86

Address for correspondence:

Salehoddin Bouya

Internal Medicine and Nephrology

Clinical Immunology Research Center

Ali-Ebne Abitaleb Hospital

Zahedan University of Medical Sciences, Zahedan, Iran

e-mail: bouya@zaums.ac.ir

\begin{abstract}
Introduction: Death anxiety is a major psychological complication among patients with chronic disease patients. The aim of the present study was to compare death anxiety between cancer, hemodialysis, and asthma patients and healthy individuals.

Material and methods: This cross-sectional study was performed on 543 subjects (88 cancer patients, 103 asthma patients, 188 hemodialysis patients, 164 healthy individuals) referred to educational hospitals in southeastern Iran in the period from August 1, 2019 to May 1, 2020. Patients were selected using the convenience sampling method. Data were collected using the Templer Death Anxiety Scale (DAS). Data analyzed using SPSS with the $\chi^{2}$ test.

Results: The results of the study showed that most of the participants were female and had a diploma. Death anxiety results showed that most participants in the groups of cancer patients ( $n=53,60.2 \%)$, hemodialysis patients $(n=113,60.1 \%)$, and asthma patients $(n=51,49.5 \%)$ had high anxiety. The prevalence of death anxiety among cancer patients was $73.8 \%$. There was no significant difference between the two groups of cancer patients and healthy individuals in terms of death anxiety scores $(p=0.3)$; however, the prevalence of death anxiety was higher among cancer patients. There was also no significant relationship of death anxiety with sex or education level of participants.

Conclusions: The high prevalence of death anxiety among cancer patients indicates the importance of paying attention to the psychological dimension of patients along with the physical dimension and designing appropriate training programs to improve the psychological dimensions of patients.
\end{abstract}

Key words: anxiety, renal dialysis, asthma, neoplasms.

\section{Introduction}

Chronic diseases are the main causes of mortality and morbidity in the world. The lead chronic diseases are: cancer, chronic kidney disease and respiratory diseases (Rudd et al. 2020). Cancer is one of the most important public health challenges in the world today. Cancers are one of the ten leading causes of death in the world. According to the latest statistics, there were more than $1,806,590$ new cancer cases and more than 606,520 cancer deaths (Siegel et al. 2020). Cancer causes different physical (muscle pain) and psychological (stress, anxiety) complications in patients (Ribeiro et al. 2020; Jiang, 2020). Anxiety of death is also one of the most common psychological reactions in hemodialysis patients and research shows that more than $63 \%$ of dialysis patients suffer from anxiety (Alshraifeen et al. 2020; Kimmel et al. 
2020). However, dialysis itself has a significant negative effect on the physical and mental dimensions of patients (Schouten et al. 2019).

Asthma is a common and complex disease that affects more than 300 million people worldwide (Khreis et al. 2019). Sudden and unexpected side effects of restricted bronchial airflow, such as asthma attacks, are a major feature of asthma, often accompanied by shortness of breath, coughing, and wheezing. Patients perceive stress as a risk factor for suffocation, which leads to long-term anxiety (Faisal and Yunus 2020).

Proper adaptation to the disease is one of the effective factors in proper disease management and reduction of complications (Tsai et al. 2020). The disease is associated with increased levels of stress, anxiety, and depression in the early stages, but due to chronic long-term effects, these complications change into anxiety and fear of death (Cook et al. 2020). Anxiety is a reaction to an unknown, internal, and ambiguous danger with an unknown origin. Breast cancer patients suffer from different types of anxieties, including death anxiety. Death anxiety is defined as the feeling of uneasiness associated with fear that is directed at one's own or others' death and is evoked by considering death as the end of life or the embodiment of the burial of a dead body (Soleimani et al. 2020). Bibi and Khalid (2020) also define death anxiety as an unusual and great fear of death. Using principal component analysis, Dunes identified five sources of adult death anxiety: fear of personal death, worry about the pain of death, mental closeness to death, death-related fears, and death-related worrying thoughts (Valikhani and Yarmohammadi-Vasel 2014). A recent metaanalysis study showed that approximately half of breast cancer patients (41.9\%) suffer from anxiety (Hashemi et al. 2020).

Death anxiety is an immediate threat to mental well-being. The study shows that the prevalence of fear of death is higher among young people than adults; therefore, these people show a stronger reaction to death anxiety (Barnett $e t$ al. 2018). Considering the importance of identifying the exact burden of death anxiety on the psychological and physical dimensions of cancer patients who do not have specific treatment, on the one hand, and helping to plan to improve the general condition of patients and reduce death anxiety, on the other hand, the present study aimed to compare death anxiety among cancer, hemodialysis, and asthma patients and healthy individuals.

\section{Material and methods}

This cross-sectional study was performed on 543 persons (88 cancer patients, 103 asthma patients, 188 hemodialysis patients, 164 healthy individuals) referred to educational hospitals in southeastern Iran between August 1, 2019 and May 1, 2020.

Patients were selected using the convenience sampling method. Inclusion criteria included patients with known cancer, hemodialysis and asthma confirmed by a specialist, and the age range of 15 to 60 years. Exclusion criterion also included lack of consent to participate in the study. The sample size was retrospectively selected using the information of patients referred to hospitals and physician offices in the past year.

The standard Templer Death Anxiety Scale (DAS) was used to assess death anxiety. The questionnaire consisted of two parts. The first part included questions on demographic characteristics: age, sex, marital status, and level of education. The second part included DAS. This instrument consisted of 15 questions with yes (1) and no (0) answers, with scores 1 and 0 indicating presence and absence of death anxiety, respectively. The possible score range was 0 (no anxiety) to 15 (very severe death anxiety). The cut-off point was set at 6-7. Scores 0-6 and 6-15 represented low and high death anxiety, respectively. The validity and reliability of DAS have been confirmed in various foreign and domestic studies.

To collect information, coordination was made with oncology, asthma, and hemodialysis wards of hospitals in question and doctors' offices after receiving the relevant letter from the university. Then, a session was held for possible participants with the help of ward officials and physicians. The study objectives were explained to the participants. Then, the DAS was distributed among the participants and they were given 15 minutes to complete the questionnaire. In the case of illiterate patients, the questionnaire was completed by the researcher. Finally, questionnaires were collected after the specified time.

The present study was approved by the Ethics Committee of Zahedan University of Medical Sciences with the ethics number: IR.ZAUMS. REC.1398.89. Written and oral consent was received from all participants and they were assured that their information would remain confidential. The STROBE checklist was used to report the study. Descriptive statistical tests (mean, standard deviation, frequency and per- 
centage) and analytical tests $\left(\chi^{2}\right)$ were used to describe the demographic characteristics of the participants. SPSS Version 18.0 for Windows (SPSS Inc., Chicago, IL, USA) was used to analyze the data. A $p$ value less than 0.05 was considered significant.

\section{Results}

All 534 participants completed the questionnaires (response rate: $100 \%)$. The mean age of patients was 50.2 years (range: 17-60 years). Most of the participants were female and had a diploma. Regarding death anxiety, the results showed that most participants in the groups of cancer patients $(n=53,60.2 \%)$, hemodialysis patients $(n=113,60.1 \%)$, and asthma patients $(n=51,49.5 \%)$ had high anxiety, and most people $(n=83,50.6 \%)$ in the healthy group also had high anxiety. The overall prevalence of death anxiety in cancer patients was $73.8 \%$, which showed that about three-quarters of patients suffer from death anxiety. The results of the chi-square test showed no significant differences between the two groups ( $p=0.33$ ) (Table 1).

Also, the results showed that there was no significant relationship between death anxiety among dialysis and cancer patients $(p=0.7)$. Also, there was no significant relationship between death anxiety in asthma and hemodialysis groups $(p=0.2)$.
With regard to the relationship between demographic characteristics and death anxiety, the results of the study showed no significant relationship between gender or education level and death anxiety (Table 2).

\section{Discussion}

The aim of the present study was to compare death anxiety among cancer patients and healthy individuals. A total of 543 patients (88 cancer patients, 103 asthma patients, 188 hemodialysis patients, 164 healthy individuals) were enrolled in the study. The results showed no significant difference between cancer patients and healthy people in terms of death anxiety. Based on the results, the highest rate of anxiety was related to people with high death anxiety. These findings are inconsistent with the findings of studies by Khezri et al. (2015) and Lee et al. (2016) but consistent with the findings of studies by Sadeghi et al. (2015). In this regard, Khezri et al. (2015) showed a significant relationship between death anxiety among cancer patients and their depression. According to the findings of this study, cancer patients have higher death anxiety than other people and the prevalence of depression is also higher in them. The findings also revealed that there are other more important factors and variables affecting patients' lives and determining their death anxiety as compared to the physical and mental conditions of cancer,

Table 1. Comparison of death anxiety in cancer patients and healthy people $(N=534)$

\begin{tabular}{lcccc} 
Anxiety & Cancer patients & Hemodialysis patients & Asthma patients & \multicolumn{2}{c}{ Healthy people } \\
& $n(\%)$ & $n(\%)$ & $n(\%)$ & $51(31.1)$ \\
No anxiety & $23(26.1)$ & $54(28.7)$ & $38(36.9)$ & $30(18.3)$ \\
\hline Moderate anxiety & $12(13.6)$ & $21(11.2)$ & $14(13.6)$ & $83(50.6)$ \\
\hline High anxiety & $53(60.2)$ & $113(60.1)$ & 103 & 164 \\
\hline Total & 88 & 188 & $51(49.5)$ & \\
\hline
\end{tabular}

Table 2. The relationship between demographic characteristics and death anxiety in the two groups

\begin{tabular}{|c|c|c|c|c|c|c|c|}
\hline \multirow[t]{2}{*}{ Variables } & \multicolumn{3}{|c|}{ Cancer patients } & \multicolumn{3}{|c|}{ Healthy peoples } & \multirow[t]{2}{*}{$P$-value } \\
\hline & No & Moderate & High & No & Moderate & High & \\
\hline \multicolumn{7}{|l|}{ Gender } & \multirow[t]{3}{*}{0.71} \\
\hline Female & $12(23.1)$ & $7(13.5)$ & $33(63.5)$ & $24(26.4)$ & 19 (20.9) & $48(52.7)$ & \\
\hline Male & $11(30.6)$ & $5(13.9)$ & $20(55.6)$ & $27(37)$ & $11(15.1)$ & $35(47.9)$ & \\
\hline \multicolumn{7}{|l|}{ Level of education } & \multirow[t]{6}{*}{0.3} \\
\hline Illiterate & $1(14.3)$ & $4(42.9)$ & $3(42.9)$ & $1(7.7)$ & $3(23.1)$ & $9(69.2)$ & \\
\hline High school & $5(33.33)$ & $1(6.7)$ & $9(60)$ & $7(30.4)$ & $5(21.7)$ & $11(47.8)$ & \\
\hline Diploma & $14(31.1)$ & $5(11.1)$ & $26(57.8)$ & $32(38.1)$ & $17(20.2)$ & 35 (41.7) & \\
\hline $\mathrm{BSC}$ & $2(11.1)$ & $3(16.7)$ & $13(72.2)$ & $6(28.6)$ & $2(9.5)$ & $13(61.9)$ & \\
\hline MSc & $1(33.3)$ & 0 & $2(66.7)$ & $5(21.7)$ & $3(13)$ & $15(65.2)$ & \\
\hline
\end{tabular}


dialysis and asthma. In this regard, it seems that factors such as socio-cultural status and religious beliefs have led to the formation of patients' beliefs and awareness regarding life and death. Accordingly, due to the religious environment of Iranian society, this group of people do not have a pessimistic view of death and consider death as a kind of right in their lives that they must finally accept; therefore, death anxiety in this group of people is not significantly different from healthy people (Razaghi et al. 2020). However, the overall death anxiety rate was relatively high. In this regard, it seems that healthy people have a relatively high death anxiety due to the impact of economic factors and poor living conditions, as well as the impact of other hidden factors and variables (Solaimanizadeh $e t$ al. 2020). Disappointment with the economic situation in today's Iranian society, the disintegration of moral boundaries in society, and the formation of a kind of socio-cultural anomie in society has caused healthy people to have high death anxiety (Jong 2020).

The results showed no significant difference between cancer patients and healthy people of both genders in terms of death anxiety. Women patients with cancer had higher rate of death anexity than male and healthy people. The results did not show a significant difference between men and women in both groups. Also, there was no significant relationship between death anxiety and age. According to the results, the highest rate of severe death anxiety among cancer patients was related to people with a bachelor's degree and the lowest rate was related to illiterate people. The highest rate of severe death anxiety among dialysis patients was related to illiterate people and the lowest rate was related to people with postgraduate education and above. According to the results, the highest rate of severe death anxiety among people with asthma was related to people holding degrees at the diploma level and the lowest rate was related to people with postgraduate education. Also, the highest rate of severe death anxiety among healthy people was related to illiterate people and the lowest rate was related to people with a diploma. The findings showed there is no significant difference between death anxiety and age, gender and education of cancer patients and healthy people. However, overall, the findings demonstrated women experience a higher rate of death anxiety than men. The findings of the present study are consistent with the findings of studies by Dadgari study (Dadgari et al. 2015), but inconsistent with the findings of other studies that showed no significant relationship between death anxiety and demographic variables, including age, sex, and education level (Mansurifard et al. 2020; Bibi and Khalid 2020; Lee et al. 2016; Bhattacharjee and Banerjee 2016). Lee et al. also showed a significant relationship between underlying factors such as rural residence, female gender, and older age and an increase in anxiety disorders. According to the findings, the underlying factors and demographic variables are not outside the social, cultural, religious, historical, and political context of Iranian society and, in fact, the absence of a significant relationship of these variables with death anxiety among patients and healthy individuals was due to the influence of these factors in the disease process (Bhattacharjee and Banerjee 2016; Naderifar et al. 2018). However, the results showed that there was a higher rate of death anxiety among female patients as compared to men. In this regard, it can be said that in Iranian society, women are considered as the second sex and they thus face higher rates of economic, social and cultural deprivation of women than men. Consequently, they suffer from higher death anxiety than men. However, there was no significant difference between men and women in this regard. Overall, caution must be exercised when interpreting the findings of the present study due to using a non-probability sampling method (convenience sampling), the disproportionate sample size in different categories, overlooking the contribution of economic, religious, social and cultural factors and other hidden variables.

\section{Conclusions}

The high prevalence of death anxiety among cancer patients indicates the importance of paying attention to the psychological dimension of patients along with the physical dimension and designing appropriate training programs to improve the psychological dimensions of patients.

\section{Informed consent}

Informed consent was obtained from all individual participants included in the study.

\section{Disclosure}

The authors declare no conflict of interest.

\section{References \\ 1. Alshraifeen A, Alnuaimi K, Al-Rawashdeh S, et al. Spiritu- ality, anxiety and depression among people receiving he-}


modialysis treatment in Jordan: a cross-sectional study. J Relig Health 2020; 59: 2414-2429.

2. Barnett MD, Anderson EA, Marsden AD $3^{\text {rd }}$. Is death anxiety more closely linked with optimism or pessimism among older adults? Arch Gerontol Geriatr 2018; 77: 169-173.

3. Bhattacharjee A, Banerjee A. State and trait anxiety among cancer patients: a comparative analysis. J Psychosoc Res 2016; 11: 427.

4. Bibi A, Khalid MA. Death anxiety, perceived social support, and demographic correlates of patients with breast cancer in Pakistan. Death Stud 2020; 44: 787-792.

5. Cook EE, Rosenberg SM, Ruddy KJ, et al. Prospective evaluation of the impact of stress, anxiety, and depression on household income among young women with early breast cancer from the Young and Strong trial. BMC Public Health 2020; 20: 1514.

6. Dadgari F, Rouhi M, Farsi Z. Death anxiety in nurses working in critical care units of AJA hospitals. Military Caring Sci J 2015; 2: 150-157.

7. Faisal HKP, Yunus F. Asthma death. Pneumologia 2020; 68: 162-168.

8. Hashemi SM, Rafiemanesh H, Aghamohammadi T, et al. Prevalence of anxiety among breast cancer patients: a systematic review and meta-analysis. Breast Cancer 2020; $27:$ 166-178.

9. Jiang Z. The consensus of physical therapeutic treatment on cancer patients. AIP Conference Proceedings, 2020. AIP Publishing LLC, 020050.

10. Jong J. Death anxiety and religion. Curr Opin Psychol 2020; 40: 40-44.

11. Khezri L, Bahreyni M, Ravanipour M, et al. The relationship between spiritual wellbeing and depression or death anxiety in cancer patients in Bushehr 2015. Nursing Vulnerable 2015; 2: 15-28.

12. Khreis H, Cirach M, Mueller N, et al. Outdoor air pollution and the burden of childhood asthma across Europe. Eur Respir J 2019; 54: 1802194.

13. Kimmel PL, Cohen SD, Cukor D. Anxiety in patients with CKD and ESRD. Psychosocial aspects of chronic kidney disease. Elsevier 2020.

14. Lee YC, Lee CT, Lai YR, et al. Association of asthma and anxiety: a nationwide population-based study in Taiwan. J Affect Disord 2016; 189: 98-105.

15. Mansurifard F, Ghaljaei F, Navidian A. The effect of spiritual care on the spiritual health of adolescents with cancer: a pre-experimental study. Med Surg Nurs J 2020; 8.

16. Naderifar M, Tafreshi MZ, Ilkhani M, et al. Correlation between quality of life and adherence to treatment in hemodialysis patients. J Renal Injury Prevent 2018; 8: 22-27.

17. Razaghi M, Chavoshian H, Chanzanagh HE, Rabiei K. Religious fundamentalism, individuality, and collective identity: a case study of two student organizations in Iran. Crit Res Relig 2020; 8: 3-24.

18. Ribeiro FE, Palma MR, Silva DTC, et al. Relationship of anxiety and depression symptoms with the different domains of physical activity in breast cancer survivors. J Affect Disord 2020; 273: 210-214.

19. Rudd KE, Johnson SC, Agesa KM, et al. Global, regional, and national sepsis incidence and mortality, 1990-2017: analysis for the Global Burden of Disease Study. Lancet 2020; 395: 200-211.

20. Sadeghi H, Saeedi M, Rahzani K, Esfandiary A. The relationship between social support and death anxiety in hemodialysis patients. Iranian J Psychiatr Nurs 2015; 2: 36-48.

21. Schouten RW, Haverkamp GL, Loosman WL, et al. Anxiety symptoms, mortality, and hospitalization in patients re- ceiving maintenance dialysis: a cohort study. Am J Kidney Dis 2019; 74: 158-166.

22. Siegel RL, Miller KD, Jemal A. Cancer statistics, 2020. CA Cancer J Clin 2020; 70: 7-30.

23. Solaimanizadeh F, Mohammadinia N, Solaimanizadeh L The relationship between spiritual health and religious coping with death anxiety in the elderly. J Relig Health 2020; 59: 1925-1932.

24. Soleimani MA, Bahrami N, Allen KA, Alimoradi Z. Death anxiety in patients with cancer: A systematic review and meta-analysis. Eur J Oncol Nurs 2020; 48: 101803.

25. Tsai LY, Tsai JM, Tsay SL. Life experiences and disease trajectories in women coexisting with ovarian cancer. Taiwan J Obstet Gynecol 2020; 59: 115-119.

26. Valikhani A, Yarmohammadi-Vasel M. The relationship between attachment styles and death anxiety among cardiovascular patients. J Kerman University Med Sci 2014; $21: 355-367$ 